\title{
Neutralization of Methyl Cation via Chemical Reactions in Low-Energy Ion-Surface Collisions with Fluorocarbon and Hydrocarbon Self-Assembled Monolayer Films
}

\author{
Árpád Somogyi, Darrin L. Smith, and Vicki H. Wysocki \\ Department of Chemistry, University of Arizona, Tucson, Arizona, USA \\ Ramon Colorado, Jr. and T. Randall Lee \\ Department of Chemistry, University of Houston, Houston, Texas, USA
}

\begin{abstract}
Low-energy ion-surface collisions of methyl cation at hydrocarbon and fluorocarbon selfassembled monolayer (SAM) surfaces produce extensive neutralization of $\mathrm{CH}_{3}^{+}$. These experimental observations are reported together with the results obtained for ion-surface collisions with the molecular ions of benzene, styrene, 3-fluorobenzonitrile, 1,3,5-triazine, and ammonia on the same surfaces. For comparison, low-energy gas-phase collisions of $\mathrm{CD}_{3}^{+}$and 3 -fluorobenzonitrile molecular ions with neutral $n$-butane reagent gas were conducted in a triple quadrupole (QQQ) instrument. Relevant MP2 6-31G*//MP2 6-31G* ab initio and thermochemical calculations provide further insight in the neutralization mechanisms of methyl cation. The data suggest that neutralization of methyl cation with hydrocarbon and fluorocarbon SAMs occurs by concerted chemical reactions, i.e., that neutralization of the projectile occurs not only by a direct electron transfer from the surface but also by formation of a neutral molecule. The calculations indicate that the following products can be formed by exothermic processes and without appreciable activation energy: $\mathrm{CH}_{4}$ (formal hydride ion addition) and $\mathrm{C}_{2} \mathrm{H}_{6}$ (formal methyl anion addition) from a hydrocarbon surface and $\mathrm{CH}_{3} \mathrm{~F}$ (formal fluoride addition) from a fluorocarbon surface. The results also demonstrate that, in some cases, simple thermochemical calculations cannot be used to predict the energy profiles because relatively large activation energies can be associated with exothermic reactions, as was found for the formation of $\mathrm{CH}_{3} \mathrm{CF}_{3}$ (formal addition of trifluoromethyl anion). (J Am Soc Mass Spectrom 2002, 13, 1151-1161) @ 2002 American Society for Mass Spectrometry
\end{abstract}

$\mathrm{L}$ ow-energy collisions of polyatomic ions with surfaces and the reaction mechanisms that charthem represent an ongoing research challenge. Detailed summaries and descriptions of ionsurface collision processes have been provided in reviews [1-3] and in recent papers by, e.g., Cooks and coworkers [4] and Hayward et al. [5]. Briefly, these processes can be classified into at least five general categories: Elastic scattering, neutralization, surfaceinduced dissociation, ion-surface atom/group transfer reactions, and chemical sputtering [4]. Reactions in each category can occur via multiple mechanisms, and often it is difficult to distinguish the various pathways $[4,5]$. The remarkably large number of proposed mechanisms provides evidence of the vast multitude of possibilities [1-9].

Published online August 21, 2002

Address reprint requests to Dr. V. H. Wysocki, Department of Chemistry, University of Arizona, Box 210041, 1306 E. University Boulevard, Tucson AZ 85721-0041, USA. E-mail: vwysocki@u.arizona.edu
Ion neutralization at surfaces is quite different from the other four processes because (1) neutralization leads to neutral species that are not detected directly by mass spectrometry, and (2) it results in a loss of ion signal that obviously affects sensitivity. There is a general consensus regarding the overall neutralization process: Neutralization of a positively charged projectile occurs via electron transfer from the surface. Although the electron-transfer mechanism is difficult to describe (for attempts, see, e.g., Reference [7] and references therein), it is supported by several experimental observations, including surface-induced dissociation (SID) efficiency measurements [1, 2, 7-9] and thermochemical and quantum chemical calculations [9]. It should be noted that ion-surface collisions of atomic projectiles with bare metal surfaces [10] must be distinguished from collisions between small organic (polyatomic) ions and a metal surface covered with an ordered (long chain) self-assembled organic monolayer (SAM). In the case of organic ions colliding with an organic surface, which is discussed in this paper, the neutralization is less exten- 
sive than that for atom/bare metal collisions. The amount of neutralization at self-assembled monolayer surfaces is roughly dependent on the energy difference between the ionization energy of the organic surface species and the recombination energy of the projectile. The amount of neutralization at fluoroalkanethiolate and alkanethiolate SAM surfaces varies, for example, in the order $\mathrm{Ar}^{+\cdot}>\mathrm{Cl}^{+}>\mathrm{CH}_{3}^{+}>$[benzene] ${ }^{+\cdot}>\mathrm{Na}^{+}\left(\mathrm{K}^{+}\right)$ [9]. Increased ion signal (less neutralization) observed on a fluoroalkanethiolate surface relative to an alkanethiolate surface has been related to the higher ionization energy of fluorinated versus hydrogenated alkyl chains $[2,8,9]$. Other related studies on $\mathrm{CF}_{3}$-terminated Langmuir-Blodgett films [11] and SAMs showed that significantly less neutralization of small organic projectile ions occurs on fluorocarbon surfaces than on hydrocarbon surfaces. These studies, which utilized SAMs such as $\mathrm{CF}_{3}\left(\mathrm{CH}_{2}\right)_{15} \mathrm{~S}$-Au and $\mathrm{CF}_{3} \mathrm{CF}_{2}\left(\mathrm{CH}_{2}\right){ }_{14} \mathrm{~S}$-Au [12] and projectiles such as benzene and pyrazine, show that a single $\mathrm{CF}_{3}$ terminal group (or a $\mathrm{CF}_{3} \mathrm{CF}_{2}$ group) at the uppermost layer of these surfaces mimics a more highly fluorinated surface (e.g., $\left.\mathrm{CF}_{3}\left(\mathrm{CF}_{2}\right)_{9} \mathrm{CH}_{2} \mathrm{CH}_{2} \mathrm{~S}-\mathrm{Au}\right)$. Note that SID experiments using isotopically labeled Langmuir-Blodgett films also led to the conclusion that predominantly the uppermost atoms or groups are involved in low-energy ion-surface reactions [13].

In the present work, the role of the terminal groups of self-assembled monolayers in ion neutralization is explored by $a b$ initio and thermochemical calculations together with experimental observations associated with the neutralization of methyl cation at several distinct SAM surfaces. The studies show that neutralization of methyl cation can occur via concerted chemical reactions, i.e., not only by direct electron transfer from the surface. (Of course, an electron must be transferred from the metal substrate to neutralize the ionized surface chain; otherwise, the surface would be charged, which has not been observed for SAMs used in our SID studies [14].) Specifically, for $\mathrm{CH}_{3}^{+}$, the following products can be formed in exothermic processes and without appreciable activation energy: $\mathrm{CH}_{4}$ (hydride ion addition), $\mathrm{C}_{2} \mathrm{H}_{6}$ (methyl anion addition), and $\mathrm{CH}_{3} \mathrm{~F}$ (fluoride addition). The studies also demonstrate that, in some cases, simple thermochemical calculations cannot be reliably used to predict the energy profiles, given that relatively large activation energy can be associated with exothermic reactions, as was found for the formation of $\mathrm{CH}_{3} \mathrm{CF}_{3}$ (trifluoromethyl anion addition).

\section{Experimental and Computational}

In experimental studies, we used perdeutero methyl cation, $\mathrm{CD}_{3}^{+}$, which was generated from $\mathrm{CD}_{3} \mathrm{I}$ or acetone- $d_{6}$ (Aldrich, Milwaukee, WI) by electron impact (EI) ionization $(70 \mathrm{eV})$. No difference was observed when $\mathrm{CD}_{3}^{+}$was generated from either $\mathrm{CD}_{3} \mathrm{I}$ or acetone$d_{6}$. Benzene, styrene, 3-fluorobenzonitrile, ammonia, and 1,3,5-triazine molecular ions were generated similarly from the corresponding neutral molecules (Al- drich). The alkanethiols investigated include alkyl-terminated $\left[\mathrm{CH}_{3}\left(\mathrm{CH}_{2}\right)_{15} \mathrm{SH}\right.$, denoted by $\left.\mathrm{C} 16 \mathrm{~F} 0\right], \mathrm{CF}_{3}-$ terminated $\left[\mathrm{CF}_{3}\left(\mathrm{CH}_{2}\right)_{15} \mathrm{SH}\right.$, denoted by $\left.\mathrm{C} 16 \mathrm{~F} 1\right], \mathrm{CF}_{3} \mathrm{CF}_{2}-$ terminated $\left[\mathrm{CF}_{3} \mathrm{CF}_{2}\left(\mathrm{CH}_{2}\right)_{14} \mathrm{SH}\right.$, denoted by $\left.\mathrm{C} 16 \mathrm{~F} 2\right]$, and $\mathrm{C}_{10} \mathrm{~F}_{21}$-terminated $\left[\mathrm{CF}_{3}\left(\mathrm{CF}_{2}\right)_{9}\left(\mathrm{CH}_{2}\right)_{6} \mathrm{SH}\right.$, denoted by $\mathrm{C} 16 \mathrm{~F} 10]$. The shortened nomenclature $\mathrm{C} 16 \mathrm{Fx}$ indicates total number of carbons (16) and the number of carbons from the alkyl terminus (x) that are perfluorinated. The normal alkanethiol, $\mathrm{CH}_{3}\left(\mathrm{CH}_{2}\right)_{15} \mathrm{SH}(92 \%)$, was purchased from Aldrich and used without further purification. The synthesis of the fluorocarbon-terminated alkanethiols has been reported elsewhere [12, 15].

Vapor-deposited gold surfaces were purchased from Evaporated Metal Films (Ithaca, NY). The gold surfaces were formed on a $17 \mathrm{~mm} \times 13 \mathrm{~mm} \times 0.5 \mathrm{~mm}$ silica base that was covered with a $5 \mathrm{~nm}$ adhesion under-layer of titanium and then $100 \mathrm{~nm}$ of vapor-deposited gold. The gold surfaces were UV-cleaned for 15 min (Boekel UV cleaner, Model 135500) before being placed in appropriate thiol solutions. Ethanolic stock solutions of the various alkanethiols $(\sim 1 \mathrm{mM})$ were prepared in glassware cleaned with piranha solution $\left(\mathrm{H}_{2} \mathrm{SO}_{4} / \mathrm{H}_{2} \mathrm{O}_{2}\right.$, in a 3:1 volume ratio; Caution: Piranha solution should be handled with extreme care!). A 6-8 $\mathrm{mL}$ aliquot of the ethanolic stock solution of a particular thiol was transferred to a new disposable test tube after the tube was UV-cleaned for $5 \mathrm{~min}$. Monolayer formation occurred by allowing the freshly UV-cleaned gold surface to react in the ethanol thiol solution for $72 \mathrm{~h}$. The films were then rinsed six times by sonication in ethanol, dried under argon, and inserted into the fast entry lock of the mass spectrometer (placed under vacuum) within 5-10 $\min$

A detailed description of the basic SID tandem mass spectrometer with recent modifications has been published elsewhere $[16,17]$. Briefly, two Extrel quadrupole mass analyzers are arranged in a $90^{\circ}$ configuration with an adjustable surface holder bisecting the mass analyzers at a $45^{\circ}$ angle. Collision energy is controlled by the potential difference between the ion source and the surface, where mass-selected singly charged ions from the first quadrupole collide into the organic thin film. The products of the collision are then focused into and analyzed by the second quadrupole of the tandem system. Ion focusing is accomplished by a set of three metal lenses placed after the first quadrupole and in front of the second quadrupole (focus ions to and from the surface). The surface holder secures four surfaces, and each surface can be individually placed in the ion beam path of the mass spectrometer. This setup allows all four surfaces to be analyzed under the same experimental conditions. During these experiments, the base pressure of the instrument was $5 \times 10^{-7}$ torr and sample pressure rarely exceeded $9 \times 10^{-7}$ torr (measured in the analysis chamber).

For neutralization studies, currents were measured with a picoamperemeter at the target surface during the collision. Elevated current at the target surface during collision indicates an enhanced electron transfer that 
neutralizes the incoming projectile ions (correspondingly, enhanced surface neutralization leads to low ion current measured at the electron multiplier of the mass spectrometer). The measurement of the extent of neutralization was the comparison of the current generated from the collision of the projectile ion beam with an UV-cleaned bare gold surface. The bare gold surface was UV-cleaned for $15 \mathrm{~min}$ and placed in absolute ethanol until inserted into the mass spectrometer. The neutralization of the projectile ion beam with a bare metal surface is assumed to be $\sim 99 \%$ efficient and independent of the projectile ion. Therefore, determining the amount of ions that are neutralized and survive the collision is expressed as the neutralized ion beam (NIB) and the surviving ion beam (SIB): \% NIB = (current for SAMs) $(99 \%) /$ (current for bare metal); $\%$ SIB $=100-\%$ NIB.

Although the absolute neutralization efficiency at a bare Au surface is not known exactly, 99\% neutralization is a reasonable assumption considering early results of SID experiments on bare metal surfaces and disordered short chain alkanethiols [1, 8]. More importantly, slight deviations from the assumed $99 \%$ value do not affect the relative SIB values for all projectile ions reported in this paper.

In our preliminary studies, external electric fields caused drift in current measurements that limited our ability to collect reproducible data. The precision of the current measurements was improved with the addition of a Faraday cage. A wire mesh (Faraday) cage was placed around the dual quadrupole SID instrument on all four sides and on the top. The cage was grounded to the vacuum chamber during the current measurements.

Ion/molecule reactions were performed in a Finnigan TSQ 700 triple quadrupole mass spectrometer (Finnigan MAT, San Jose, CA). Product ion mass spectra were recorded by mass selecting an ion of interest using the first quadrupole and allowing the ion to pass through the second quadrupole (rf-only), which contained a reagent gas. The third quadrupole was scanned over the mass range of interest at a rate of one second/ scan. The ion source and vacuum manifold were held at $150{ }^{\circ} \mathrm{C}$ and $70^{\circ} \mathrm{C}$, respectively. The collision cell offset potential was set to produce a low-energy laboratory collision of $4 \mathrm{eV}$. The reagent gas used for reaction was $n$-butane (+99\%, Aldrich), which was introduced directly into the collision quadrupole by linking the $n$-butane lecture bottle regulator to the collision cell gas port on the TSQ. The pressure of the reagent gas was controlled with the TSQ leak valve and maintained at $\sim 1.4$ mTorr.

The closed shell methyl cation is sufficiently small for quantum chemical calculations. Unfortunately, even one surface chain of the SAM is too large for high-level ab initio calculations on our university processors. However, the similarity of SID and gas-phase collision experiments $[8,18]$ and reactions occurring between [benzene] ${ }^{+\cdot}$ cation and ${ }^{13} \mathrm{CH}_{3^{-}}, \mathrm{CD}_{3^{-}}$, and $\mathrm{CF}_{3}$-terminated Langmuir-Blodgett [11, 13] and self-assembled monolayer films [12] indicate that primarily the upper-

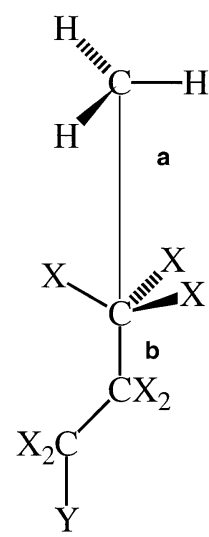

$\mathbf{X}, \mathbf{Y}=\mathbf{H}, \mathbf{C H}_{3}$ $\mathbf{X}, \mathbf{Y}=\mathbf{F}, \mathbf{F}$

Scheme 1a

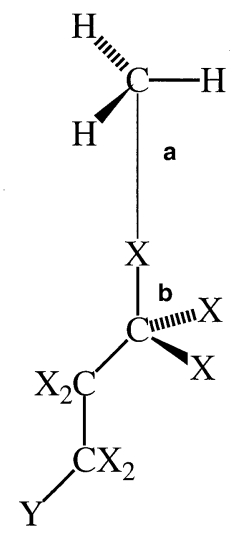

Scheme 1b

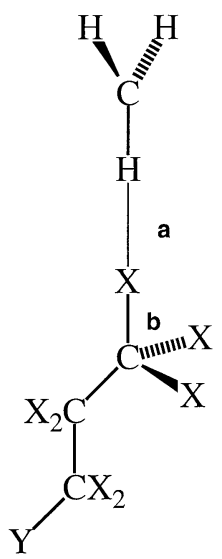

Scheme 1c most atoms or group of a surface chain are involved in low-energy ion-surface reactions. These observations justify the use of smaller compounds to model the surface chain. We used $n-\mathrm{C}_{4} \mathrm{H}_{10}$ to model an alkanethiolate surface and $\mathrm{C}_{3} \mathrm{~F}_{8}$ to model a fluorinated alkanethiolate surface (Scheme 1). [For comparison purposes, specifically for the addition of $\mathrm{CF}_{3}$ (trifluoromethyl anion), we also used $\mathrm{CH}_{3} \mathrm{CH}_{2} \mathrm{CH}_{2} \mathrm{CF}_{3}$ to model the $\mathrm{CF}_{3}$-terminated $\mathrm{CF}_{3}\left(\mathrm{CH}_{2}\right)_{15} \mathrm{~S}$-Au surface.] The experimental observation of charged reaction products indicates that the projectile ion slows down and stays at the vicinity of the surface (2-3 $\AA$ ) for at least one vibrational period (ca. $10^{-13} \mathrm{~s}$ ). This feature justifies the use of the Born-Oppenheimer approximation, i.e., these reactions can be modeled by the time-independent Schrödinger equation. Strictly speaking, our computational model below assumes that projectile ions have low kinetic energy in close vicinity of the surface during the neutralization. Of course, a percentage of higher energy ions can exist and can exit the potential energy surface (PES) at higher energy pathways.

Although in real ion-surface collisions a large number of random orientations are possible, the three specific orientations illustrated in Schemes $\mathbf{1 a}, \mathbf{b}$, and $\mathbf{c}$ were considered in the present work. As will be shown, these orientations are reasonable models for describing certain characteristic features of ion-surface reactions and projectile neutralization. All calculations were performed at the MP2 6-31G* level by using the program package Gaussian 94 [19]. The potential energy surfaces were calculated by changing the $-\mathrm{CX}_{3} \ldots \mathrm{CH}_{3}$ distance and the $-C X_{2} \ldots C X_{3}$ distance (distances $a$ and $b$ in Scheme 1a, respectively). All other geometry parameters were optimized assuming the retention of $C_{s}$ symmetry during the model reaction. Note again that the $\mathrm{C}_{\mathrm{s}}$ symmetry restriction may introduce some artifacts in the potential energy surfaces. However, we believe that such an arbitrarily chosen symmetry restriction is a better approximation for a "real" ion-surface reaction because the rotation of the "reacting" chain (or upper- 

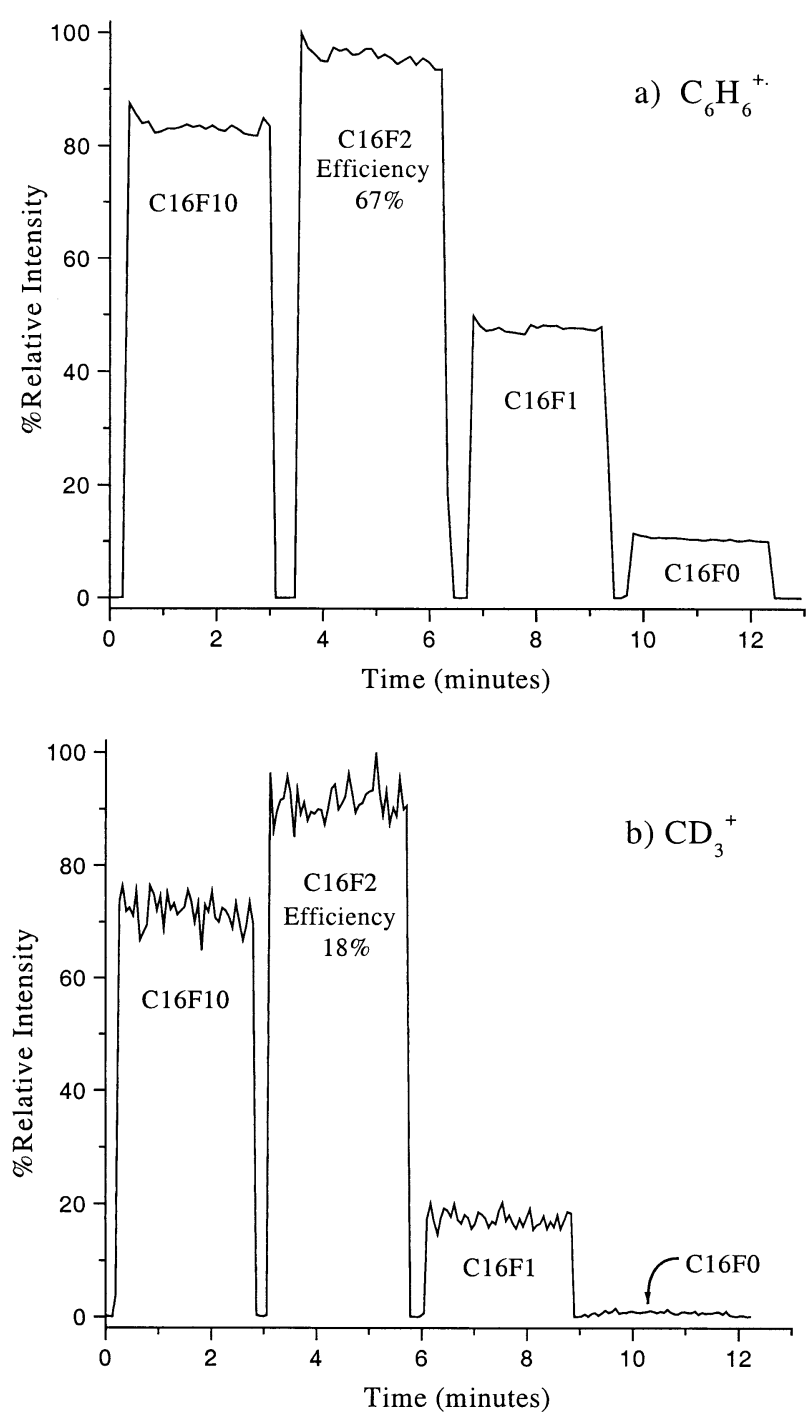

Figure 1. The total scattered-ion current (TIC) was measured at the detector of the SID instrument for (a) benzene radical cation ([benzene $]^{+\cdot}$ ) and (b) perdeutero methyl cation $\left(\mathrm{CD}_{3}^{+}\right)$collided at $30 \mathrm{eV}$ kinetic energy into $\mathrm{C}_{10} \mathrm{~F}_{21}$-terminated (C16F10), $\mathrm{CF}_{3} \mathrm{CF}_{2^{-}}$ terminated $(\mathrm{C} 16 \mathrm{~F} 2), \mathrm{CF}_{3}$-terminated $(\mathrm{C} 16 \mathrm{~F} 1)$, and alkyl-terminated (C16F0) SAM films. The time axis represents the actual acquisition time of the ion-surface collision experiments, i.e., $\sim 3$ min of acquisition time for each surface.

most group) is hindered by neighboring chains (or groups) in a well-ordered SAM film.

\section{Results and Discussion}

\section{Experimental Results}

Figures $1 \mathrm{a}$ and $\mathrm{b}$ show the total scattered-ion current (TIC) recorded by the detector of the SID tandem mass spectrometer when [benzene] ${ }^{+\cdot}$ and $\mathrm{CD}_{3}^{+}$cations, respectively, were collided at $30 \mathrm{eV}$ SID energy with four distinct SAM surfaces. The corresponding $30 \mathrm{eV}$ product ion spectra recorded for the $\mathrm{CD}_{3}^{+}$cation at two surfaces $(\mathrm{C} 16 \mathrm{~F} 2$ and $\mathrm{C} 16 \mathrm{~F} 0)$ are shown in Figure 2.

The comparison of Figure 1a and Figure 1b indicates
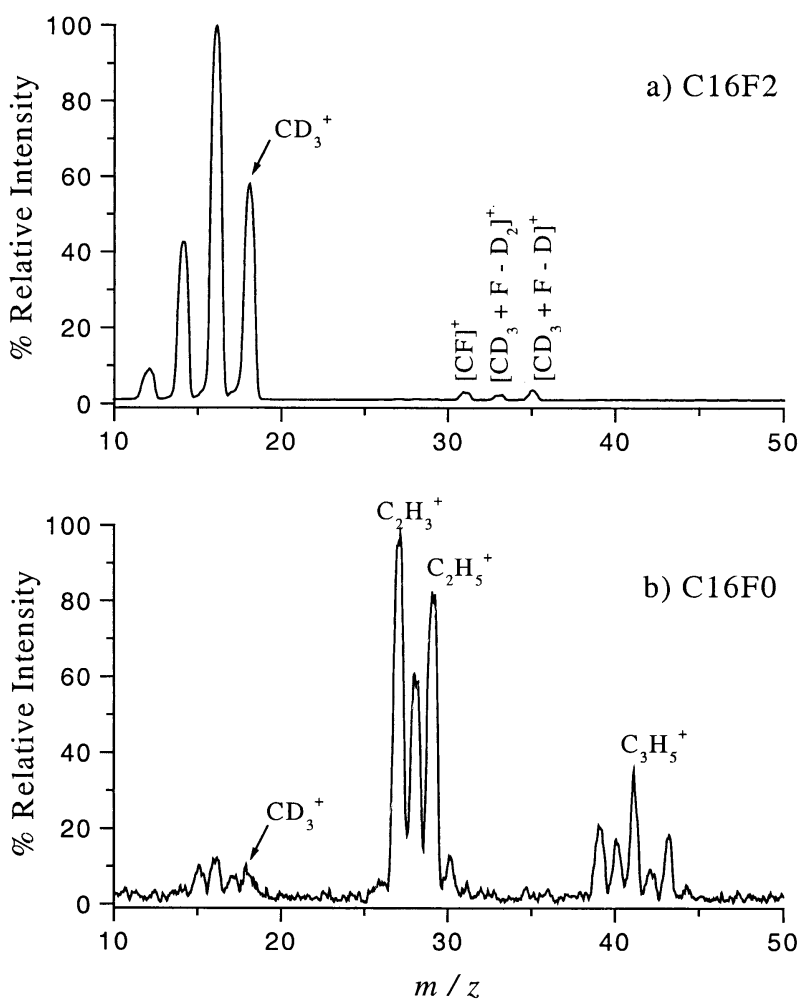

Figure 2. Product spectra formed by collision between perdeutero methyl cation $\left(\mathrm{CD}_{3}^{+}\right)$at $30 \mathrm{eV}$ kinetic energy with (a) $\mathrm{CF}_{3} \mathrm{CF}_{2-}^{-}$ terminated (C16F2) and (b) alkyl-terminated (C16F0) SAM films.

both the similarities and differences between the total scattered-ion current of [benzene] ${ }^{+\cdot}$ and $\mathrm{CD}_{3}^{+}$cations with the same hydrocarbon and fluorocarbon surfaces. The highest ion recovery (i.e., the least amount of neutralization) was observed for both cations at the $\mathrm{CF}_{3} \mathrm{CF}_{2}$-terminated surface, $\mathrm{C} 16 \mathrm{~F} 2$ (Figure 1). A closer look at the TIC results in Figure 1 reveals important differences between the neutralization of [benzene] ${ }^{+}$ and $\mathrm{CD}_{3}^{+}$. Although a general trend exists for the two cations with the hydrocarbon and fluorocarbon surfaces, the measured SIB percentage values are characteristically different. (For the definition of \% SIB, see the Experimental and Computational section). For [benzene $^{+*}, \sim 67 \%$ SIB was measured at the C16F2 surface, which is in remarkably good agreement with the SID efficiency $\left(\mathrm{I}_{\mathrm{ev}} / \mathrm{I}_{0}\right)$ results published earlier for a C12F10 surface [8]. The corresponding \% SIB value obtained at the same surface for the $\mathrm{CD}_{3}^{+}$cation is only $\sim 18 \%$. These data were collected three independent times with the present instrumental setup and are highly reproducible. Consistently, the signal-to-noise $(\mathrm{S} / \mathrm{N})$ ratio is much better in the benzene product-ion spectra (spectra not shown for [benzene] ${ }^{+\cdot}$ but also manifested in the lower variability of signal intensity on the top of the TIC curves in Figure 1a versus 1b).

Interestingly, $30 \mathrm{eV}$ collisions with the "more fluorinated" surface (C16F10) resulted in slightly lower TIC current for both projectiles than obtained for the C16F2 surface. This small difference may be related to slight 
differences in the conformation and packing density of these surfaces. In particular, recent analyses by atomic force microscopy (AFM) have found that the lattice spacing of the $\mathrm{CF}_{3} \mathrm{CF}_{2}$-terminated $\mathrm{SAM}$ is $\sim 5.0 \AA$ (i.e., indistinguishable from that of normal alkyl-terminated SAMs on gold) and the lattice spacing of the $\mathrm{C}_{10} \mathrm{~F}_{21^{-}}$ terminated SAM is $\sim 5.8 \AA$ [20-23].

The $\mathrm{C} 16 \mathrm{~F} 1$ surface is also interesting because it exhibits different TIC behavior toward [benzene $]^{+\cdot}$ versus $\mathrm{CD}_{3}^{+}$cations. If the $\% \mathrm{SIB}$ value for each projectile with the C16F1 surface is normalized to the $\mathrm{C} 16 \mathrm{~F} 2$ surface $\%$ SIB value, the normalized \% SIB ratio (C16F2: $\mathrm{C} 16 \mathrm{~F} 1)$ for benzene is 1.0:0.62 while the same ratio for the methyl cation is 1.0:0.27. Previous ion-surface collisions studies with pyrazine molecular ion with the C16F1 surface have shown that hydrogen atoms (from the $\mathrm{CH}_{2}$ group under the $\mathrm{CF}_{3}$ group) are exposed and available for reaction [12]. Therefore, the origin of the TIC difference (increase of neutralization of methyl cation) with the $\mathrm{C} 16 \mathrm{~F} 1$ surface is at least in part from the smaller size of $\mathrm{CD}_{3}^{+}$versus [benzene] ${ }^{+*}$. The steric difference permits more facile reaction of the methyl cation with the second-layer (highly reactive) $\mathrm{CH}_{2}$ groups leading to the formation of neutral reaction products (as previously mentioned and explained in detail below). Although more neutralization (lower TIC) is observed at the C16F1 surface (with only a $\mathrm{CF}_{3}$-terminal group) than for the $\mathrm{C} 16 \mathrm{~F} 10$ and $\mathrm{C} 16 \mathrm{~F} 2$ surfaces for both projectiles, it is also clear from Figure 1 that the inclusion of only one $\mathrm{CF}_{3}$ terminal group characteristically improves ion survival compared to normal alkyl-terminated surfaces (C16F0).

Another notable difference between the TICs of [benzene] ${ }^{+\cdot}$ and $\mathrm{CD}_{3}^{+}$is that the TIC obtained at the hydrocarbon surface $(\mathrm{C} 16 \mathrm{~F} 0)$ is only slightly above baseline for $\mathrm{CD}_{3}^{+}$, but clearly above baseline for [benzene $]^{+*}$. Although it was difficult to measure the $\%$ SIB for the $\mathrm{CD}_{3}^{+}$cation at the $\mathrm{C} 16 \mathrm{~F} 0$ alkanethiolate surface, it is unquestionably less than $1.0 \%$. Accordingly, the $\mathrm{CD}_{3}^{+}$cation is virtually missing from the product ion spectrum, and mostly sputtered ions (alkyl chain fragments from the surface) are detected at $30 \mathrm{eV}$ SID collision energy (see Figure $2 b$ ). On the other hand, the $\mathrm{S} / \mathrm{N}$ ratio is better in the product ion spectrum of $\mathrm{CD}_{3}^{+}$ obtained with the $\mathrm{C} 16 \mathrm{~F} 2$ partially fluorinated surface (Figure 2a). In this spectrum, $\mathrm{CD}_{3}^{+}$and its fragments are the dominant ions. The presence of ions at $\mathrm{m} / \mathrm{z} 31,33$, and 35 indicates fluoride addition and subsequent fragmentation of the reaction product (see labels in Figure 2a). The F-addition reaction products were verified with ion-surface collisions utilizing the unlabeled methyl cation $\left(\mathrm{CH}_{3}^{+}\right)$. However, the presence of the ion at $\mathrm{m} / z 31$ $\left(\mathrm{CF}^{+}\right)$could be a combination of fragmented reaction product as well as sputtering from the fluorocarbon SAM surface.

It is important to note again that the \% SIB values for $\mathrm{CD}_{3}^{+}$have been found to be characteristically and consistently lower than those obtained for [benzene] ${ }^{+}$ on the same surface. The $\%$ SIB values are: $18 \pm 2 \%$ for

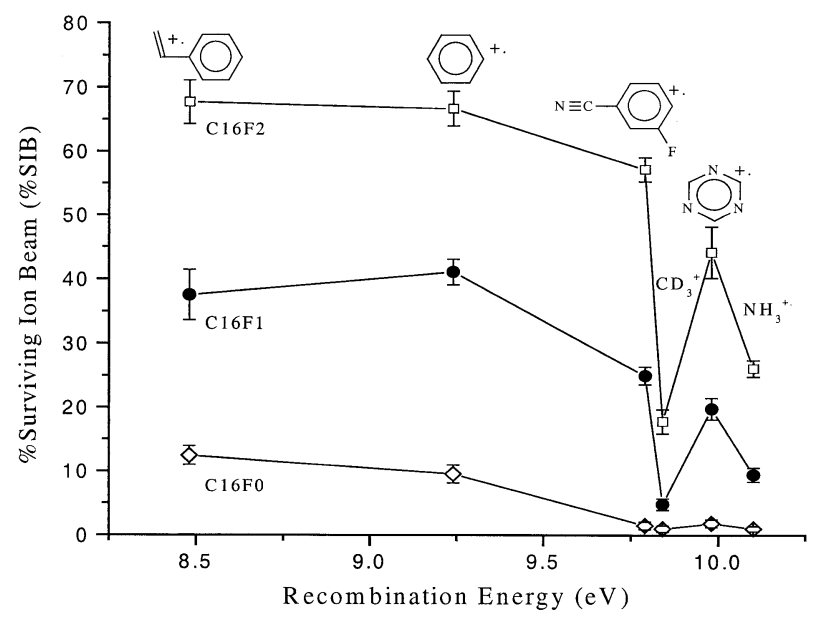

Figure 3. Percentage surviving ion beam (\% SIB) as a function of the recombination energy of selected projectile ions. These results were generated by collisions between the projectile ions at $20 \mathrm{eV}$ SID energy with (a) $\mathrm{CF}_{3} \mathrm{CF}_{2}$-terminated (C16F2: open squares), (b) $\mathrm{CF}_{3}$-terminated (C16F1: closed circles), and (c) alkyl-terminated (C16F0: open diamonds) SAM surfaces.

$\mathrm{CD}_{3}^{+}$and $67 \pm 3 \%$ for $\mathrm{C}_{6} \mathrm{H}_{6}^{+\cdot}$ on the fluorocarbon $(\mathrm{C} 16 \mathrm{~F} 2)$ surface; $<1.0 \%$ for $\mathrm{CD}_{3}^{+}$and $9.5 \pm 1.4 \%$ for $\mathrm{C}_{6} \mathrm{H}_{6}^{+\cdot}$ on the hydrocarbon (C16F0) surface. The large difference in SID efficiency for $\mathrm{CD}_{3}^{+}$versus [benzene] ${ }^{+}$. is surprising given the relatively small difference between the ionization energies [24] of $\mathrm{CH}_{3}(9.84 \mathrm{eV})$ and benzene $(9.25 \mathrm{eV})$. Based on a simple electron-transfer mechanism, i.e., relying simply on the difference between the ionization energy of the SAM surface and the recombination energy of the projectile, the neutralization of $\mathrm{CH}_{3}^{+}$at a fluorinated surfaces is predicted to be strongly endothermic while the same process at alkanethiolate surfaces is weakly endothermic. These simple calculations, which will be discussed below in greater detail, indicate that processes other than simple electron transfer might play a role in the neutralization of $\mathrm{CH}_{3}^{+}$ at fluorocarbon and hydrocarbon SAM surfaces.

To further explore the role of the SAM ionization energy and the recombination energy of the projectile, we performed low energy ion-surface collision experiments for four additional projectile ions having recombination energies (RE) that lie in the range of ca. 8.5-10.1 $\mathrm{eV}$ [24]. (Note that, strictly speaking, the recombination energies are not known directly for all ions of interest; therefore, the ionization energies of the corresponding neutrals (molecules or radicals) are assumed to be the recombination energies in this paper. By convention, we use positive RE values, even though ion recombination is related to energy release.) These projectiles include the molecular ions of styrene $(\mathrm{RE}=8.45 \mathrm{eV})$, 3-fluorobenzonitrile $(\mathrm{RE}=9.78 \mathrm{eV}), 1,3,5$-triazine $(\mathrm{RE}=9.95$ $\mathrm{eV})$, and $\mathrm{NH}_{3}(\mathrm{RE}=10.10 \mathrm{eV})$. The \% SIB values as a function of recombination energies for three different SAM surfaces $(\mathrm{C} 16 \mathrm{~F} 2, \mathrm{C} 16 \mathrm{~F} 1$, and $\mathrm{C} 16 \mathrm{~F} 0)$ are shown in Figure 3. The general trend is a decreasing \% SIB with increasing recombination energy. The $\mathrm{CD}_{3}^{+}$cation con- 
sistently exhibits much lower \% SIB values than would be expected given its recombination energy. For example, although the recombination energy of the 3-fluorobenzonitrile molecular ion is almost the same as that of $\mathrm{CD}_{3}^{+}(9.78 \mathrm{eV}$ versus $9.84 \mathrm{eV})$, there is a significant difference in the \% SIB values obtained for these cations. We selected the $\mathrm{NH}_{3}^{+\cdot}$ cation to mimic the geometry and size of the small $\mathrm{CH}_{3}^{+}$cation, although one can argue that the difference in electron parity (i.e., the open electron structure $\mathrm{NH}_{3}^{+\cdot}$ and the closed shell $\mathrm{CH}_{3}^{+}$) might give rise to different neutralization processes. In a recent related study [25], the surviving ion beam (\% SIB) results generated with oxygen-containing projectiles (1,4-dioxane: $\mathrm{RE}=9.19 \mathrm{eV}$ and acetone: $\mathrm{RE}=9.70$ $\mathrm{eV}$ ) on the same surfaces have shown ion-neutralization behavior that deviates from the trend in Figure 3 (e.g., C16F2: $\%$ SIB $\sim 44 \%$ for 1,4 -dioxane and $\sim 43 \%$ for acetone). Taken as a whole, these data suggest that ion neutralization is dependent on the atomic composition and/or structure of the projectile ions. The \% SIB results for oxygen-containing projectiles are still substantially higher when compared to the results for methyl cation. In any case, the \% SIB values obtained for the projectiles presented in Figure 3 support the assumption that processes other than a "simple" electron transfer might also take place during $\mathrm{CH}_{3}^{+}$neutralization at SAM surfaces.

As was mentioned in the Experimental section, we also conducted certain low energy ion-molecule reactions in a Finnigan triple quadrupole instrument. Figure 4a shows the resulting spectrum from ion-molecule reactions between (neutral) $n$-butane reagent gas and $\mathrm{CD}_{3}^{+}$. The base peak in this spectrum is the butyl cation at $\mathrm{m} / \mathrm{z} 57$. The low intensity peak at $\mathrm{m} / \mathrm{z} 18$ corresponds to the $\mathrm{CD}_{3}^{+}$cation. No fragmentation of $\mathrm{CD}_{3}^{+}$is observed, which is not surprising given that the collision cell offset potential was set to produce a $4 \mathrm{eV}$ laboratory collision in these experiments. At higher collision energies (up to $9 \mathrm{eV}$ ), more $\mathrm{m} / \mathrm{z} 18$ survives the collision (the $\mathrm{m} / \mathrm{z} 18 / 57$ ratio increases) suggesting that low collision energies favor a reactive long-lived collision complex that allows the formal hydride transfer [26]. Some low intensity butane fragment ions $(\mathrm{m} / \mathrm{z} 43,41$, and 29) also appear in the spectrum. These fragments mimic the sputtered ions in the SID experiments described above. In the $70 \mathrm{eV}$ EI spectrum of $\mathrm{C}_{4} \mathrm{H}_{10}^{+}$, the intensity of the fragment ion at $\mathrm{m} / \mathrm{z} 57$ is much lower than that of the molecular ion (spectrum not shown). We therefore conclude that the ion at $\mathrm{m} / \mathrm{z} 57$ originates predominantly from a specific hybrid transfer ion-molecule reaction that is associated with the formation of neutral methane [26]: $\mathrm{CD}_{3}^{+}+\mathrm{C}_{4} \mathrm{H}_{10} \rightarrow \mathrm{CD}_{3} \mathrm{H}+\mathrm{C}_{4} \mathrm{H}_{9}^{+}$.

This experiment demonstrates that this reaction is preferred in the gas-phase and suggests that an analogous reaction can also occur at alkanethiolate selfassembled monolayer surfaces (see above).

For comparison, we also conducted an ion-molecule reaction between neutral $n$-butane reagent gas and the molecular ion of 3-fluorobenzonitrile $(\mathrm{RE}=9.78 \mathrm{eV})$ in
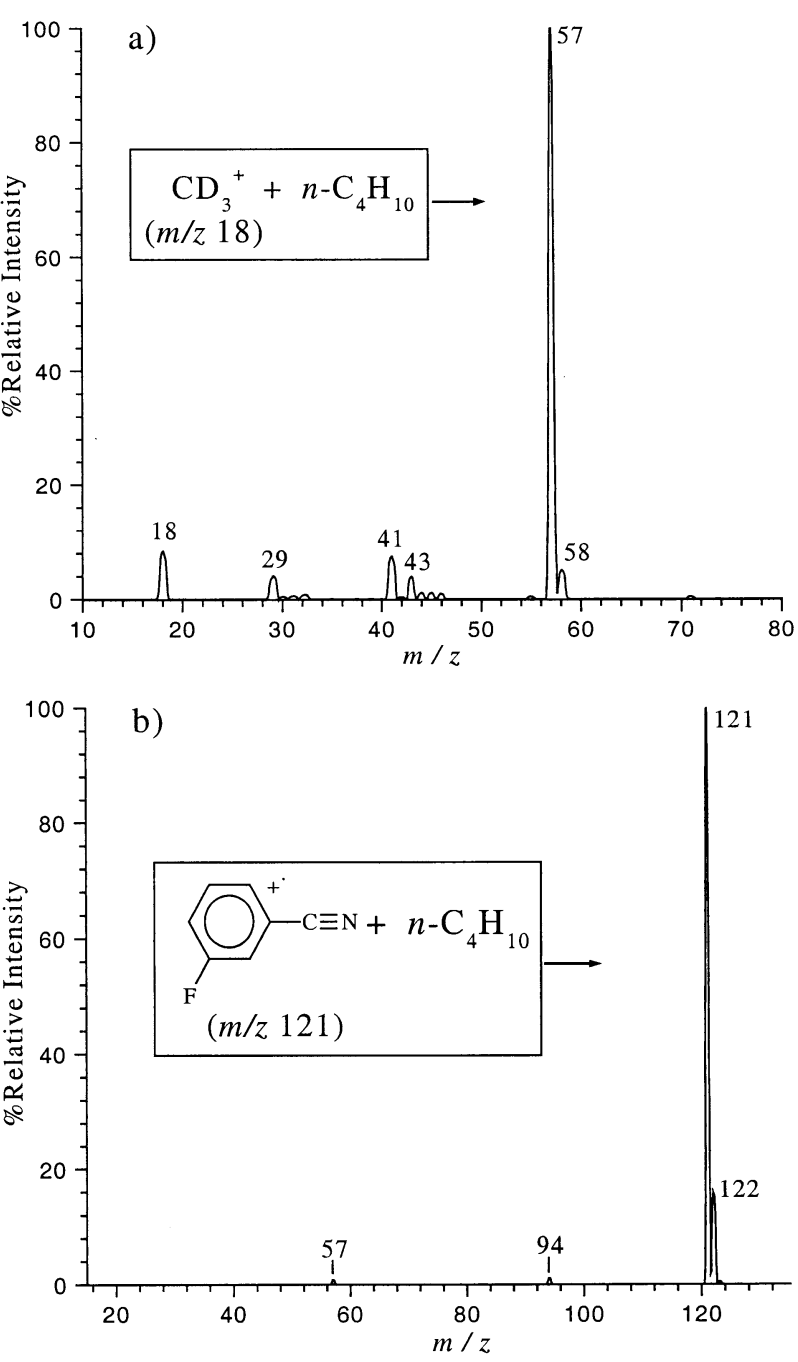

Figure 4. Spectra generated from ion-molecule reactions between $n$-butane reagent gas and (a) perdeutero methyl cation $(\mathrm{m} / \mathrm{z}$ $18)$ and (b) 3-fluorobenzonitrile ion $(\mathrm{m} / \mathrm{z} 121)$ in a Finnigan triple quadrupole instrument. In both cases, the collision cell offset potential was set to produce a low-energy laboratory collision of 4 $\mathrm{eV}$.

the triple quadrupole instrument. The resulting spectrum is shown in Figure $4 \mathrm{~b}$. In strong contrast to the spectrum of Figure 4a, the intensity of the peak at $m / z 57$ is extremely low $(<2 \%)$, and the base peak is the 3 -fluorobenzonitrile molecular ion $(\mathrm{m} / \mathrm{z} 121)$. These results are consistent with the SID results discussed above: Although the recombination energies of $\mathrm{CD}_{3}^{+}$ and 3-fluorobenzonitrile are nearly indistinguishable ( $9.84 \mathrm{eV}$ versus $9.79 \mathrm{eV}$ ) [24], much less neutralization is observed for the 3-fluorobenzonitrile ion than for the $\mathrm{CD}_{3}^{+}$ion.

\section{Computational Results}

To provide theoretical support for some of the possible alternative neutralization processes of $\mathrm{CH}_{3}^{+}$at these surfaces, we performed a series of MP2 $6-31 \mathrm{G}^{*} / / \mathrm{MP} 2$ $6-31 G^{*}$ ab initio calculations. Three different orienta- 


\section{$\left[\mathrm{CH}_{3} \mathrm{CH}_{2} \mathrm{CH}_{2} \mathrm{CH}_{3} \ldots \mathrm{CH}_{3}\right]^{+}$}

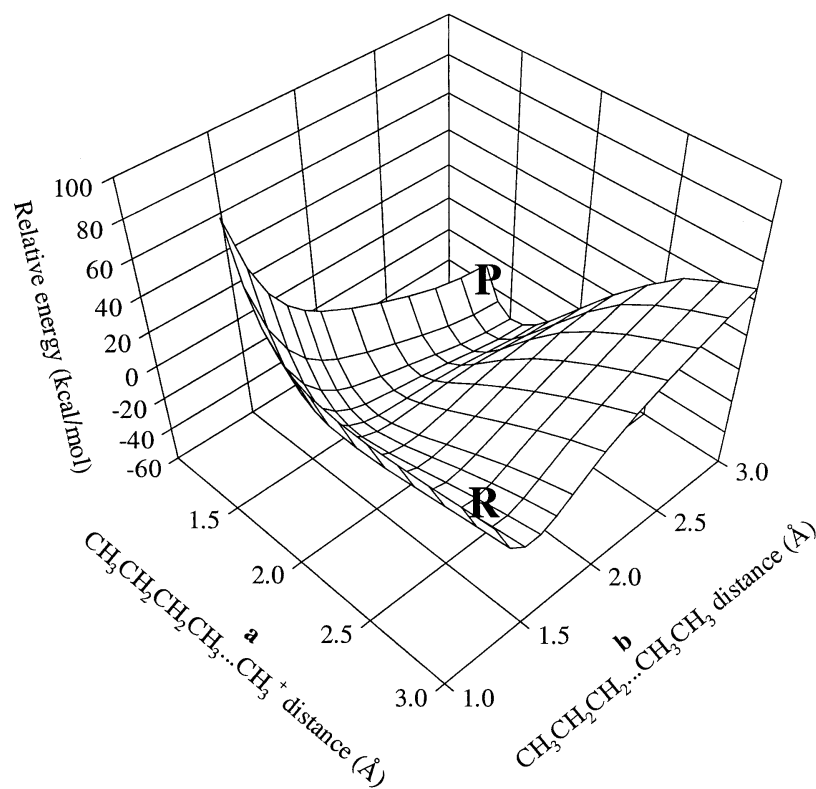

Figure 5. MP2 6-31G*//MP2 6-31G* potential energy surface was generated for a model collision between $\mathrm{CH}_{3}^{+}$and $n-\mathrm{C}_{4} \mathrm{H}_{10}$. Parameters $\mathrm{a}$ and $\mathrm{b}$ in Scheme 1a were varied over the range of 1.3-3.0 A. $\mathrm{R}$ indicates the reactants $\left(\mathrm{CH}_{3}^{+}\right.$and $\left.\mathrm{C}_{4} \mathrm{H}_{10}\right)$, and $\mathrm{P}$ indicates the products $\left(\mathrm{CH}_{3} \mathrm{CH}_{3}+\mathrm{C}_{3} \mathrm{H}_{7}^{+}\right)$.

tions were modeled as shown in Scheme 1a, b, and c. In all cases, the $\mathrm{CH}_{3}^{+}$approaches the surface (represented by distance a). Preliminary calculations [9] showed that as the $\mathrm{CH}_{3}^{+}$approaches the surface with the "chain" orientations shown in Scheme $\mathbf{1 a}$ and $\mathbf{b}$, the $\mathrm{CH}_{2}-\mathrm{CH}_{3}$ carbon bond of the alkanethiolate model surface (Scheme 1a) and the $\mathrm{C}-\mathrm{H}$ bond of the uppermost methyl group of the surface (Scheme $\mathbf{1 b}$ ) are significantly elongated. Therefore, in the present work, we used these bond lengths (represented by $b$ in Schemes 1a and $\mathbf{b})$ as a second variable parameter to obtain two-dimensional potential energy surfaces. With a similar approach, we used the $\mathrm{CH}_{3} \mathrm{CH}_{2} \mathrm{CH}_{2} \mathrm{CH}_{2}$. . H distance (distance $\mathrm{b}$ in Scheme 1c) to model a head-on collision.

Figure 5 shows the MP2 6-31G* / MP2 6-31G* potential energy surface obtained for the model reaction between methyl cation and $\mathrm{CH}_{3} \mathrm{CH}_{2} \mathrm{CH}_{2} \mathrm{CH}_{3}$ in the "reactive" configuration shown in Scheme 1a, $(X=H$, $\mathrm{Y}=\mathrm{CH}_{3}$ ). This reaction models the formation of neutral $\mathrm{CH}_{3} \mathrm{CH}_{3}$ by the methyl cation (abstraction of $-\mathrm{CH}_{3}$ from the surface chain). The lower left axis of Figure 5 indicates the distance between the $\mathrm{CH}_{3}^{+}$projectile and the surface (distance a in Scheme 1a), while the right axis (distance $b$ in Scheme 1a) indicates the $\mathrm{CH}_{2}-\mathrm{CH}_{3}$ carbon-carbon bond length of the cleaving alkyl chain. The reference energy $(0 \mathrm{kcal} / \mathrm{mol})$ is the sum of the MP2 6-31G $\mathrm{G}^{*} / / \mathrm{MP} 26-31 \mathrm{G}^{*}$ total energy of $n-\mathrm{C}_{4} \mathrm{H}_{10}$ and $\mathrm{CH}_{3}^{+}$. The reference energy is the energy of the system at infinite surface-projectile distance and is virtually un- changed until $\mathrm{CH}_{3}^{+}$approaches the surface closer than ca. $4 \AA$. (In other words, ca. $4 \AA$ is the distance at which the methyl cation starts to "see" or "feel" the surface.) An important feature of the potential energy surface in Figure 5 is that the system is rolling downhill, i.e., the methyl anion addition reaction proceeds with no activation barrier to produce neutral ethane and a charged surface $\left(\mathrm{C}_{3} \mathrm{H}_{7}^{+}\right.$in our model, see product side, $\mathrm{P}$, in Figure 5). Although the number of $\mathrm{C}-\mathrm{C}$ and $\mathrm{C}-\mathrm{H}$ bonds is the same in both the reactants and products, the exothermicity of this reaction is due to the increased "delocalization" of the positive charge in $\mathrm{C}_{3} \mathrm{H}_{7}^{+}$relative to $\mathrm{CH}_{3}^{+}$. Unfortunately, the neutral product, ethane, goes undetected by the mass spectrometer, but the measured low SID efficiency value for $\mathrm{CH}_{3}^{+}$(i.e., the loss of $\sim 99 \%$ of $\mathrm{CH}_{3}^{+}$ion current) is consistent with the theoretical prediction. Strictly speaking, the potential energy surface in Figure 5 is valid if there is no "spontaneous" or "concurrent" rearrangement(s) of the ionized surface chain. Although we have no evidence to exclude such a rearrangement, intuitively one can assume that it would require a longer time, especially for highly packed SAM chains so that the formed neutral $\left(\mathrm{CH}_{3} \mathrm{CH}_{3}\right)$ can already be far away from the surface.

It should be noted that in the SID spectrum of $\mathrm{CH}_{3}^{+}$ obtained on the hexadecanethiolate (C16F0) surface (Figure $2 \mathrm{~b}$ ), chemical sputtering peaks are seen almost exclusively. Sputtered ions originating from the surface are also good indicators of projectile neutralization because a prerequisite for their formation is a transfer of the charge from the projectile to the surface (together with a significant internal energy transfer to the surface to cleave the $\mathrm{C}-\mathrm{C}$ bonds of the surface chains). The formation of the sputter peaks could originate from direct electron transfer and/or hydride ion transfer with the methyl ion (similar to the fragment peaks observed from the $\mathrm{C}_{4} \mathrm{H}_{10}$ during the ion-molecule reactions experiment). The presence of sputtered peaks in Figure $1 \mathrm{~b}$ could support a direct electron-transfer $\left(\mathrm{CH}_{3}^{+}\right.$ $+\mathrm{C}_{4} \mathrm{H}_{10} \rightarrow \mathrm{CH}_{3}+\mathrm{C}_{4} \mathrm{H}_{10}^{+\cdot}$ ) argument and may contradict the formation of neutral ethane (or methane, see below) predicted by the ab initio calculations.

Note, however, that in contrast to neutralization of $\mathrm{CH}_{3}^{+}$via the formation of ethane, direct electron transfer is a slightly endothermic process (Figure 6). Based on experimental heats of formation for the reactants and products [24], the reaction enthalpies for the formation of ethane $\left(\mathrm{CH}_{3}^{+}+\mathrm{C}_{4} \mathrm{H}_{10} \rightarrow \mathrm{CH}_{3} \mathrm{CH}_{3}+\mathrm{C}_{3} \mathrm{H}_{7}^{+}\right)$and the direct electron transfer (from $n-\mathrm{C}_{4} \mathrm{H}_{10}$ to $\mathrm{CH}_{3}^{+}$producing $\mathrm{CH}_{3}$ and $n-\mathrm{C}_{4} \mathrm{H}_{10}^{+\cdot}$ ) are -40.2 and $16.7 \mathrm{kcal} / \mathrm{mol}$, respectively (Figure 6). Note that the exothermicity of the reaction leading to $\mathrm{CH}_{3} \mathrm{CH}_{3}$ and $\mathrm{C}_{3} \mathrm{H}_{7}^{+}$may be underestimated if the rearrangement of $\mathrm{C}_{3} \mathrm{H}_{7}^{+}$(SAM chain) is possible. We must emphasize that we do not claim that all $\mathrm{CH}_{3}^{+}$cation is neutralized via the formation of ethane (or methane, see below). With reference to the reaction enthalpies discussed above (Figure 6) and the lack of an ab initio reaction barrier, we conclude that, particularly at low collision energies, the neutral- 


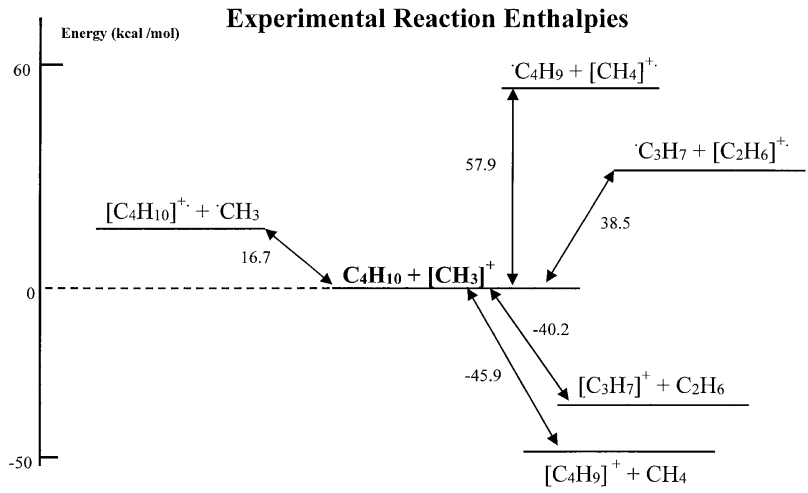

Figure 6. Reaction enthalpies of some possible reactions between $\mathrm{CH}_{3}^{+}$and $n-\mathrm{C}_{4} \mathrm{H}_{10}$. All values are based on experimental heats of formation taken from Reference [24].

ization of methyl cation via the formation of neutral ethane (or methane) can compete with direct electron transfer from $n-\mathrm{C}_{4} \mathrm{H}_{10}$ to $\mathrm{CH}_{3}^{+}$. (At higher collision energies, however, the energy of the real system might lie above the calculated potential energy surface shown in Figure 5; consequently, this surface will not be useful in predicting processes that occur at higher energies.)

Although not shown here, a MP2 6-31G*//MP2 6-31G* potential energy surface (similar to the formation of ethane, Figure 5) was obtained for the hydride ion addition reaction that leads to the formation of $\mathrm{CH}_{4}$ and $\mathrm{C}_{4} \mathrm{H}_{9}^{+}$(Scheme $\mathbf{1 b}, \mathrm{X}=\mathrm{H}, \mathrm{Y}=\mathrm{CH}_{3}$ ). Again, this reaction is calculated to have no activation barrier, which suggests that the formation of $\mathrm{CH}_{4}$ is an alternative reaction pathway for neutralizing methyl cation. The hydride ion addition reaction is also predicted to be exothermic based on experimental heats of formation $(-45.9 \mathrm{kcal} / \mathrm{mol}$, Figure 6). Its existence is supported by the ion-molecule results (intense formation of butyl ion, $m / z=57$, in Figure 4a) obtained using $\mathrm{CD}_{3}^{+}$collisions with neutral $n$-butane gas in which the major detected product is $\mathrm{C}_{4} \mathrm{H}_{9}^{+}$(presumably $\mathrm{CD}_{3}^{+}+\mathrm{C}_{4} \mathrm{H}_{10} \rightarrow \mathrm{C}_{4} \mathrm{H}_{9}^{+}+$ $\mathrm{CD}_{3} \mathrm{H}$ ). Intuitively, hydride ion addition to form methane should be sterically favored over the abstraction of methyl anion to form ethane.

The "head on" collision (i.e., H...H, Scheme 1c) is shown as (1) a MP2 $6-31 G^{*} / / M P 2$ 6-31G* potential energy surface as well as (2) a contour graph for better visualization in Figure 7. The potential energy surface is highly repulsive (notice the absolute values of the relative energies at short $a$ and $b$ distances in Scheme 1c), which indicates energy deposition to both the projectile and the surface (kinetic energy/potential energy, $\mathrm{T}-\mathrm{V}$, conversion). Two pathways from reactants (R) to products (P1 or P2) are illustrated in Figure 7. Path 1 (P1) shows a collision in which the surface $\mathrm{C}-\mathrm{H}$ bond

\section{$\left[\mathrm{CH}_{3} \mathrm{CH}_{2} \mathrm{CH}_{2} \mathrm{CH}_{2} \ldots \mathrm{H} \ldots \mathrm{H}-\mathrm{CH}_{2}\right]^{+}$}

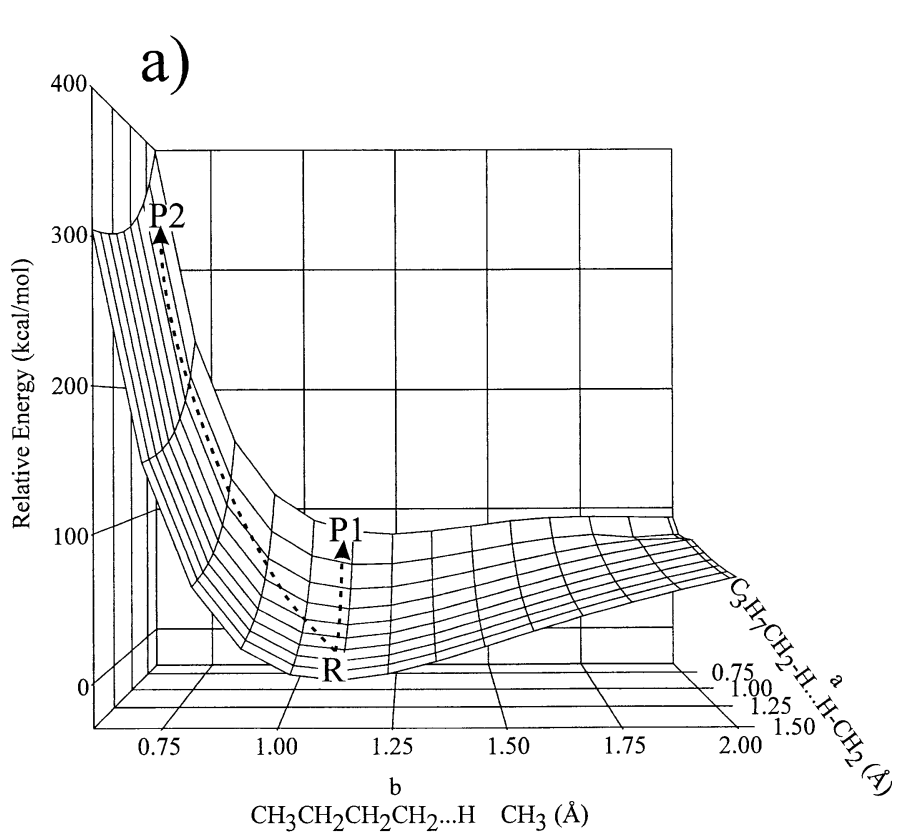

b)

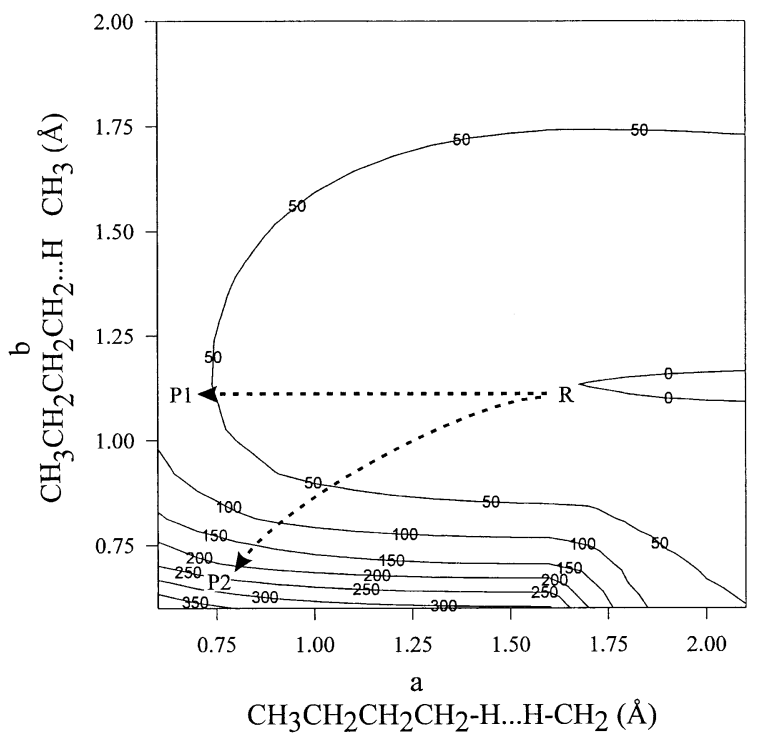

Figure 7. (a) MP2 6-31G*//MP2 6-31G* potential energy surface and (b) contour graph was generated for a "head on" $\left(\mathrm{H}\right.$. . .H) collision between $\mathrm{CH}_{3}^{+}$and $n-\mathrm{C}_{4} \mathrm{H}_{10}$. Parameters a and $\mathrm{b}$ in Scheme 1c were varied over the range of 0.75-3.0 A. Two pathways are illustrated in Figure 7 as reaction pathways going from reactants $(\mathrm{R})$ to products (P1 or P2). Path 1 (P1) shows a collision in which the surface $\mathrm{C}-\mathrm{H}$ bond (distance b) is held constant at ca. 1.1 A. Path 2 (P2) shows when the surface C-H bonds are distorted during the collision. 


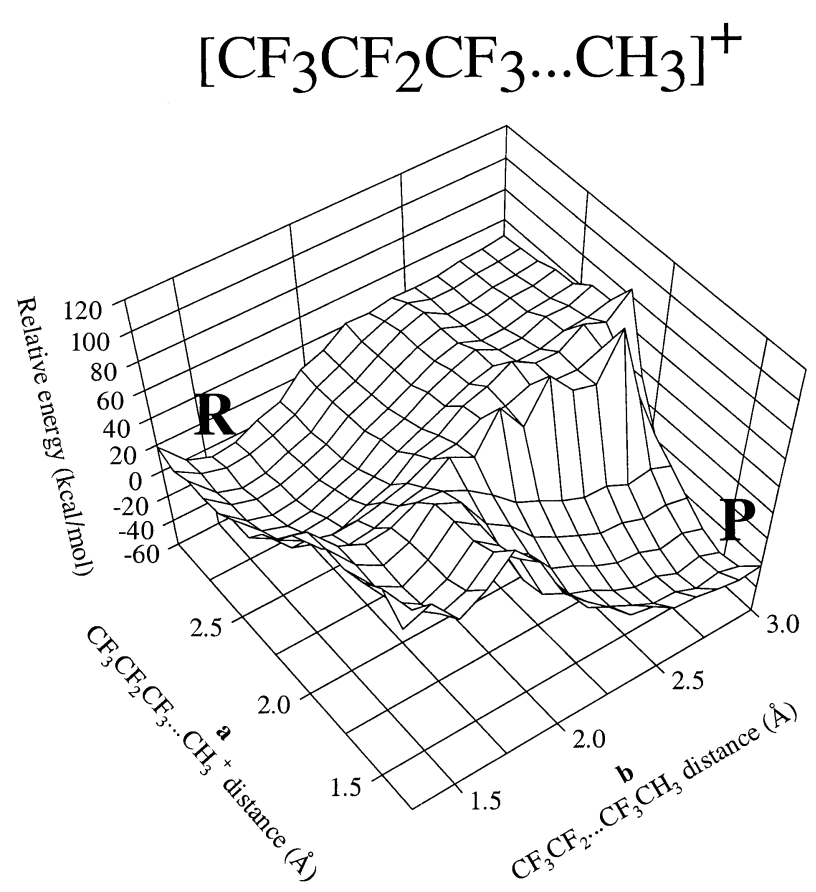

Figure 8. MP2 6-31G*//MP2 6-31G* potential energy surface for a model collision between $\mathrm{CH}_{3}^{+}$and $\mathrm{C}_{3} \mathrm{~F}_{8}$. Parameters a and $\mathrm{b}$ in Scheme 1a were varied over the range of 1.3-3.0 $\mathrm{A}$. $\mathrm{R}$ indicates the reactants $\left(\mathrm{CH}_{3}^{+}\right.$and $\left.\mathrm{C}_{3} \mathrm{~F}_{8}\right)$, and $\mathrm{P}$ indicates the products $\left(\mathrm{CH}_{3} \mathrm{CF}_{3}\right.$ $+\mathrm{C}_{2} \mathrm{~F}_{5}^{+}$).

(distance b) is held constant at ca. $1.1 \AA$. With this rigid surface, the relative energy increases as the methyl cation approaches the surface (decrease in distance a). In reality, the surface bonds are also distorted during the collision, and the energy of the system is highly repulsive (Path 2) and can even exceed $10 \mathrm{eV}(>240$ $\mathrm{kcal} / \mathrm{mol}$ ). The calculations also show that the "head on" collision between H. . .H atoms (Scheme 1c) fails to give neutralization ( $\sim 60 \%$ of the charge still remains on the methyl cation even at a H. . .H distance of $0.6 \AA$.) These results, together with those discussed above, suggest that the outcome of low-energy ion-surface reactions (e.g., neutralization versus energy deposition) depends on the relative orientation of the projectile and the outermost group of the surface.

Figure 8 shows the MP2 6-31G*//MP2 6-31G* potential energy surface calculated for the reaction, $\mathrm{CH}_{3}^{+}+$ $\mathrm{C}_{3} \mathrm{~F}_{8} \rightarrow \mathrm{CH}_{3} \mathrm{CF}_{3}+\mathrm{CF}_{2} \mathrm{CF}_{3}^{+}$, which is the "fluorinated" analog of the ethane formation described above. The orientation is shown in Scheme 1a $(X=F, Y=F)$, and both parameters $a$ and $b$ were varied over the range of 1.3-3.0 A. In Figure 8, the left axis represents the approach of $\mathrm{CH}_{3}^{+}$to the fluorocarbon chain (parameter a in Scheme 1a), and the right axis represents the cleavage of the $\mathrm{CF}_{3} \mathrm{CF}_{2} \ldots \mathrm{CF}_{3}$ bond (parameter $\mathrm{b}$ in Scheme 1a). In contrast to Figure 5, the potential energy surface in Figure 8 indicates that the addition of $\mathrm{CF}_{3}$ (trifluoromethyl anion), i.e., the neutralization of $\mathrm{CH}_{3}^{+}$ by the formation of $\mathrm{CH}_{3} \mathrm{CF}_{3}$, possesses a substantial activation barrier (ca. $60 \mathrm{kcal} / \mathrm{mol}$ ). It is important to

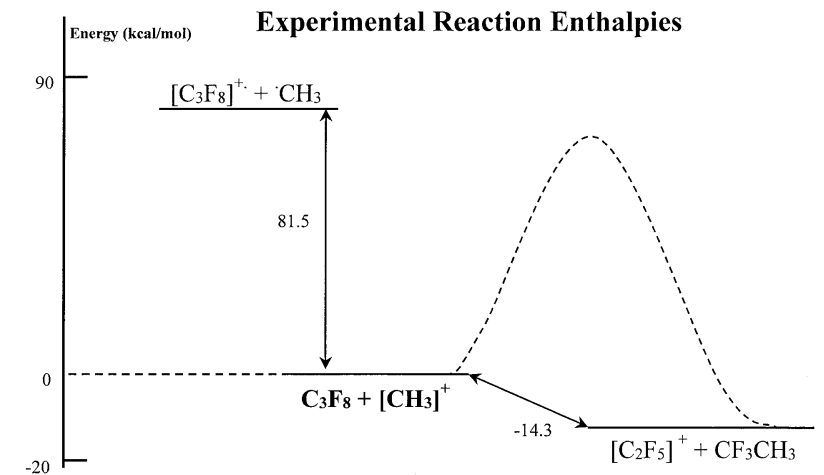

(a)

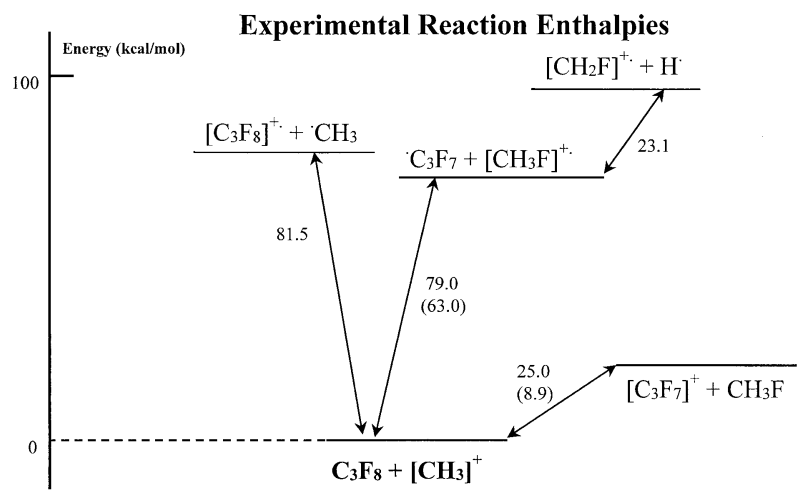

(b)

Figure 9. (a) Comparison between reaction enthalpies of a charge-exchange process and a $\mathrm{CF}_{3}$-(trifluoromethyl anion) addition process for the collision between $\mathrm{CH}_{3}^{+}$and $\mathrm{C}_{3} \mathrm{~F}_{8}$. All values are based on experimental heats of formation taken from Reference [24]. (b) Reaction enthalpies calculated for some possible reactions between $\mathrm{C}_{3} \mathrm{~F}_{8}$ and $\mathrm{CH}_{3}^{+}(0 \mathrm{kcal} / \mathrm{mol}$ reference energy). All values are based on experimental heats of formation taken from Reference [24]. Two values are shown for the reactions $\mathrm{C}_{3} \mathrm{~F}_{7}$ $+\left[\mathrm{CH}_{3} \mathrm{~F}\right]^{+}$and $\left[\mathrm{C}_{3} \mathrm{~F}_{7}\right]^{+}+\mathrm{CH}_{3} \mathrm{~F}$, which are based on two different estimations of the heats of formation for $\mathrm{C}_{3} \mathrm{~F}_{7}^{+}(-96.8 \mathrm{kcal} / \mathrm{mol}$ [24c] and $-80.8 \mathrm{kcal} / \mathrm{mol}$ [24c]) where the former value corresponds to the value in the parentheses.

note that the reaction $\mathrm{CH}_{3}^{+}+\mathrm{C}_{3} \mathrm{~F}_{8} \rightarrow \mathrm{CH}_{3} \mathrm{CF}_{3}+$ $\mathrm{CF}_{2} \mathrm{CF}_{3}^{+}$is predicted to be exothermic by simple thermochemical calculations using experimental heats of formation $\left(\Delta \mathrm{H}_{\mathrm{r}}=-14.3 \mathrm{kcal} / \mathrm{mol}\right.$, Figure 9a) [24], which highlights an important limitation of using "simple" thermochemical calculations.

A similar energy surface with a similar barrier has been calculated for the reaction $\mathrm{CH}_{3}^{+}+$ $\mathrm{CF}_{3} \mathrm{CH}_{2} \mathrm{CH}_{2} \mathrm{CH}_{3} \rightarrow \mathrm{CH}_{3} \mathrm{CF}_{3}+\mathrm{CH}_{2} \mathrm{CH}_{2} \mathrm{CH}_{3}^{+}$; the results (potential surface not shown, but it is similar to energy surface shown in Figure 8) demonstrate the importance of the terminal $\mathrm{CF}_{3}$ group. The origin of the barrier for addition of $-\mathrm{CF}_{3}$ to $\mathrm{CH}_{3}^{+}$(from $\mathrm{C}_{3} \mathrm{~F}_{8}$ or $\mathrm{CH}_{3} \mathrm{CH}_{2} \mathrm{CH}_{2} \mathrm{CF}_{3}$ ) can be associated with the lone pairs of the $\mathrm{F}$ atoms of the outermost $\mathrm{CF}_{3}$ group of a fluorinated chain, i.e., to molecular orbitals that are formed by the lone pairs of $\mathrm{F}$ atoms. We can visualize these orbitals as "umbrella" or "shield" orbitals that prevent the "penetration" of the empty orbital of the methyl cation in line with the $\mathrm{CF}_{2}-\mathrm{CF}_{3}$ bond. Because of the 
lack of such an interaction, neither the direct neutralization ("flow" of electrons from the surface to the projectile) nor the addition of $\mathrm{CF}_{3}$ (trifluoromethyl anion) is a preferred process. Such an interaction between appropriately aligned carbon orbitals is unhindered when hydrogen atoms are present (as in regular hydrocarbons), which explains why calculations show that both hydride ion and methyl anion addition occur. These additions allow extensive neutralization of methyl cation with alkanethiolate surfaces [2, 8, 9]. Of course, a strictly linear arrangement is unnecessary for the reactions with $\mathrm{CH}_{3}^{+}$; a slight "off-axis" approach (i.e., when the $a, b$ angle deviates from 180 degrees) can also lead to similar products. The importance of orbital interactions has been recognized, for example, for ion reactions at clean and oxygen-modified Ni (111) surfaces [7].

No energy barrier was predicted at the MP2 6-31G*/ / MP2 6-31G* level for the addition of fluoride, i.e., for the reaction $\mathrm{CH}_{3}^{+}+\mathrm{CF}_{3} \mathrm{CF}_{2} \mathrm{CF}_{3} \rightarrow \mathrm{CH}_{3} \mathrm{~F}+\mathrm{CF}_{2} \mathrm{CF}_{2} \mathrm{CF}_{3}^{+}$ (potential energy surface not shown, but it is similar to that shown in Figure 5). The favored formation of $\mathrm{CH}_{3} \mathrm{~F}$ can rationalize why methyl cation survival is much lower (ca. $12 \%$ ) than benzene survival (ca. $68 \%$ ) on the fluorinated surface (see Figure 1). As shown in Figure $9 \mathrm{~b}$, experimental heats of formation predict the reaction $\mathrm{CH}_{3}^{+}+\mathrm{CF}_{3} \mathrm{CF}_{2} \mathrm{CF}_{3} \rightarrow \mathrm{CH}_{3} \mathrm{~F}+\mathrm{CF}_{2} \mathrm{CF}_{2} \mathrm{CF}_{3}^{+}$to be slightly endothermic although there is an ambiguity in the heats of formation of $\mathrm{C}_{3} \mathrm{~F}_{7}$ and $\mathrm{C}_{3} \mathrm{~F}_{7}^{+}$[24]. However, the analogous reaction, $\mathrm{CH}_{3}^{+}+\mathrm{CF}_{3} \mathrm{CF}_{3} \rightarrow \mathrm{CH}_{3} \mathrm{~F}+\mathrm{CF}_{2} \mathrm{CF}_{3}^{+}$, is thermoneutral $\left(\Delta \mathrm{H}_{\mathrm{r}}=0.7 \mathrm{kcal} / \mathrm{mol}\right)$. For the molecular ion of benzene, a similar interaction is sterically more hindered, i.e., the "reactive configuration" between the benzene molecular ion and the outermost $\mathrm{CF}_{3}$ group of the fluorinated surface is statistically less favorable than other orientations that lead to $\mathrm{T}-\mathrm{V}$ conversion. Nevertheless, the reactive orientation is still accessible. The addition of fluorine to benzene molecular ion has been observed in SID spectra on fluorinated surfaces at relatively low abundance [8], but the neutralization of [benzene] ${ }^{+\cdot}$ is not associated with this reaction.

\section{Conclusions}

The experimental and computational results presented in this paper indicate that neutralization of $\mathrm{CH}_{3}^{+}$cation can occur by two types of processes: (1) Direct electron transfer from the SAM surface and (2) concerted chemical reactions without activation barriers. The decreasing neutralization of methyl cation on fluorocarbon surfaces relative to hydrocarbon surfaces can be attributed to the presence of lone pairs on the $\mathrm{F}$ atoms of the terminal $\mathrm{CF}_{3}$ groups. The lone pairs inhibit the direct electron-transfer process (from the SAM to $\mathrm{CH}_{3}^{+}$) and the direct formation of $\mathrm{CH}_{3} \mathrm{CF}_{3}$. The computational results also indicate that the relative orientation of the projectile influences the "outcome" of the modeled ion-surface reactions. Be- cause most of the SAM (and/or Langmuir-Blodgett) surfaces used in SID studies are well ordered, as characterized by various techniques such as AFM, STM, and wettability, their "static" behavior is independent of the projectile ion. The "dynamic" behavior, however, is the result of the interaction of the projectile ion and the outermost layer of the surface chains. Several ion-surface group orientations can lead to different processes, such as (1) "T-V" orientations, in which energy deposition is preferred (see, head-on collision model, Scheme 1c), and (2) "neutralization" or "reactive" orientations in which interactions between orbitals of the ion and the surface are allowed. These orbital interactions can then lead to either simple electron transfer or chemical reactions, the products of which can be neutrals (see, examples for the formation of $\mathrm{CH}_{3} \mathrm{CH}_{3}, \mathrm{CH}_{4}$, and $\mathrm{CH}_{3} \mathrm{~F}$ ) or charged species (see, e.g., fluorine, $\mathrm{F}$, addition in Figure 2). From the point of view of the projectile, we can describe a "reactivity" (or "neutralization") volume, which is a part of space in the vicinity of the ion within which a reaction with a reactive partner is allowed. Although this volume is "dynamic" rather than "static" in character, one can intuitively assume that the smaller the projectile, the larger this volume (with reference to the projectile size). For methyl cation, for example, this "reactive" volume can be defined as a "cone" above and below the plane of the cation. For a much larger projectile, e.g., for a protonated peptide, only small and local "volumes" can be reactive but are sterically hindered by the atoms of groups of the projectile. It is not surprising, therefore, that no ion-surface reactions have been reported for protonated peptides. Note that while "odd electron" molecular ions of common organic compounds are reported to be reactive, the "odd electron" character is not a prerequisite for reactivity (see our present example, the methyl cation).

Even if they are carried out on small model systems, theoretical calculations can be helpful in describing and predicting the relative contributions of the different processes that dominate low-energy ion-surface collisions (for example, molecular dynamics modeling of energy deposition of various projectile ions at diamond and SAM surfaces $[27,28]$ ) and might also contribute to the development of more sophisticated models that can be used to describe low-energy ion-surface reactions.

\section{Acknowledgments}

This work was supported by National Science Foundation grants CHE 9224719 (VHW) and DMR-9700662 (TRL). Finnigan TSQ 700 triple quadrupole mass spectrometers donated by Dr. Robert C. Murphy from the National Jewish Medical and Research Center (Denver, CO) and Dr. John Yates III from Scripps Research Institute (La Jolla, CA) are greatly appreciated by the authors. They also acknowledge Lori Smith for the initial troubleshooting of the TSQs. 


\section{References}

1. Cooks, R. G.; Ast, T.; Mabud, A. M. Collisions of Polyatomic Ions with Surfaces. Int. J. Mass Spectrom. Ion Processes 1990, 100, 209-265.

2. Cooks, R. G.; Ast, T.; Pradeep, T.; Wysocki, V. H. Reactions of Ions with Organic-Surfaces. Acc. Chem. Res. 1994, 27, 316-323.

3. Dongré, A. R.; Somogyi, Á.; Wysocki, V. H. Surface-Induced Dissociation: An Effective Tool to Probe Structure, Energetics and Fragmentation Mechanisms of Protonated Peptides. J. Mass Spectrom. 1996, 31, 339-350.

4. Ast, T.; Pradeep, T.; Feng, B.; Cooks, R. G. Low-Energy Collisions of Methane Ions at a Fluoroalkyl Monolayer Surface. J. Mass Spectrom. 1996, 31, 791-801.

5. Hayward, M. J.; Park, F. D. S.; Phelan, L. M.; Bernasek, S. L.; Somogyi, Á.; Wysocki, V. H. Examination of Sputtered Ion Mechanisms Leading to the Formation of $\mathrm{C}_{7} \mathrm{H}_{7}+$ During Surface-Induced Dissociation (SID) Tandem Mass Spectrometry (MS/MS) of Benzene Molecular Cations. J. Am. Chem. Soc. 1996, 118, 8375-8380.

6. (a) Burroughs, J. A; Wainhaus, S. B.; Hanley, L. Impulsive Excitation of $\mathrm{Cr}(\mathrm{CO})_{6}+$ During Surface-Induced Dissociation at Organic Monolayers. J. Phys. Chem 1994, 98, 10913-10919.(b) Burroughs, J. A; Wainhaus, S. B.; Hanley, L. Impulsive Excitation of $\mathrm{FeCP}_{2}+\mathrm{AND} \mathrm{SiMe}_{3}+$ During Surface-Induced Dissociation at Organic Multilayers. J. Phys. Chem 1995, 103, 6706-6715.

7. Wainhaus, S. B.; Burroughs, J. A.; Hanley, L. Charge Transfer During Pyridine Ion Scattering Off Clean and Oxygen Modified Ni (111). Surf. Sci. 1995, 344, 122-130.

8. Somogyi, Á.; Kane, T. E.; Ding, J.-M.; Wysocki, V. H. Reactive Collisions of $\mathrm{C}_{6} \mathrm{H}_{6}^{++}$and $\mathrm{C}_{6} \mathrm{D}_{6}^{++}$at Self-Assembled Monolayer Films Prepared on Gold from n-Alkanethiols and a Fluorinated Alkanethiol-the Influence of Chain Length on the Reactivity of the Films and the Neutralization of the Projectile. J. Am. Chem. Soc. 1993, 115, 5275-5283.

9. Somogyi, Á.; Shillady, D. D.; Kane, T. E.; Wysocki, V. H.. Proceedings of the 42nd ASMS Conference on Mass Spectrometry and Allied Topics, Chicago, IL. 1994; p 578.

10. Rabalais, J. W, Ed. Low Energy Ion-Surface Interactions. John Wiley and Sons: New York, 1994.

11. Gu, C.; Wysocki, V. H.; Harada, A.; Takaya, H.; Kumadaki, I. Dissociative and Reactive Hyperthermal Ion-Surface Collisions with Langmuir-Blodgett Films Terminated by $\mathrm{CF}_{3}\left(\mathrm{CH}_{2}\right)_{\mathrm{n}}$, n-Perfluoroalkyl, or n-Alkyl Groups. J. Am. Chem. Soc. 1999, 121, 10554-10562.

12. Smith, D. L.; Wysocki, V. H.; Colorado, R., Jr.; Shmakova, O. E.; Graupe, M.; Lee, T. R. Low-Energy Ion-Surface Collisions Characterize Alkyl and Fluoroalkyl-Terminated SelfAssembled Monolayers on Gold. Langmuir 2002, 18, 38953902.

13. Gu, C.; Wysocki, V. H. Ion-Surface Reactions Involving Isotopically Labeled Langmuir-Blodgett Films. J. Am. Chem. Soc. 1997, 119, 12010-12011.

14. Kane, T. E.; Wysocki, V. H. Surface-Induced Dissociation and Ion-Surface Reactions at Insulating Surfaces. Int. J. Mass Spectrom. Ion Processes 1994, 140, 177-184.

15. Graupe, M.; Koini, T.; Wang, V. Y.; Nassif, G. M.; Colorado, R., Jr.; Villazana, R. J.; Dong, H.; Miura, Y. F.; Shmakova, O. E.;
Lee, T. R. Terminally Perfluorinated Long-Chain Alkanethiols. J. Fluorine Chem. 1999, 93, 107-115.

16. Wysocki, V. H.; Ding, J. M.; Jones, J. L.; Callahan, J. H.; King, F. L. Surface-Induced Dissociation in Tandem Quadrupole Mass Spectrometers-A Comparison of Three Designs. J. Am. Soc. Mass Spectrom. 1992, 3, 27-32.

17. Angelico, V. J.; Mitchell, S. A.; Wysocki, V. H. Low-Energy Ion-Surface Reactions of Pyrazine with Two Classes of SelfAssembled Monolayers: Influence of Alkyl Chain Orientation. Anal. Chem. 2000, 72, 2603-2608.

18. Pradeep, T.; Riederer, D. E., Jr.; Hoke, S. H.; Ast, T.; Cooks, R. G.; Linford, M. R. Reactions of Metal-Ions at Fluorinated Surfaces - Formation of $\mathrm{MF}_{\mathrm{n}}^{+}(\mathrm{M}=\mathrm{Ti}, \mathrm{Cr}, \mathrm{Fe}, \mathrm{Mo}$, and $\mathrm{W}, \mathrm{n}=$ 1-5). J. Am. Chem. Soc. 1994, 116, 8658-8665.

19. Gaussian 94, Revision D.2. Frisch, M. J.; Trucks, G. W.; Schlegel, H. B.; Gill, P. M. W.; Johnson, B.G.; Robb, M. A.; Cheeseman, J. R.; Keith, T.; Petersson, G. A.; Montgomery, J. A.; Ragavachari, K; Al-Laham M. A.; Zakrzewski, V. G.; Ortiz, J. V.; Foresman, J. B.; Cioslowski, J.; Stefanov, B. B.; Nanayakkara, A.; Challacombe, M.; Peng, C. Y.; Ayala, P.Y.; Chen Y.; Wong, M. W.; Andres, J. L.; Replogle, E. S.; Comperts, R.; Martin, R. L.; Fox, D. J.; Binkley, J. S.; Defrees, D. J.; Baker, J.; Stewart, J. P.; Head-Gordon, M.; Gonzalez, C.; Pople, J. A. Gaussian, Inc., Pittsburgh, PA, 1995.

20. Fukushima, H.; Seki, S.; Nishikawa, T.; Takiguchi, H.; Tamada, K.; Abe, K.; Colorado, R., Jr.; Graupe, M.; Shmakova, O. E.; Lee, T. R. Microstructure, Wettability, and Thermal Stability of Semifluorinated Self-Assembled Monolayers (SAMs) on Gold. J. Phys. Chem. B 2000, 104, 7417-7423.

21. Tamada, K.; Ishida, T.; Knoll, W.; Fukushima, H.; Colorado, R., Jr.; Graupe, M.; Shmakova, O. E.; Lee, T. R. Molecular Packing of Semifluorinated Self-Assembled Monolayers on Gold: Influence of Alkyl Spacer Length. Langmuir 2001, 17, 1913-1921.

22. Frey, S.; Heister, K.; Zharnikov, M.; Grunze, M.; Tamada, K.; Colorado, R., Jr.; Graupe, M.; Shmakova, O. E.; Lee, T. R. Structure of Self-Assembled Monolayers of Semifluorinated Alkanethiols on Gold and Silver Substrates. Israel J. Chem. 2000, 40, 81-97.

23. Yam, C.-M.; Colorado, R., Jr.; Perry, S. S.; Lee, T. R. unpublished. See also references [20-22].

24. (a) Ionization energies and heats of formation: http://webbook. nist.gov/chemistry. b Lias, S. G.; Bartmess, J. E.; Liebman, J. F.; Holmes, J. L.; Levin, R. D.; Mallard, W. G.; J. Phys. Chem. Ref. Data 1988, 17, Suppl. 1. c Lias, S. G.; Bartmess, J. E.; Liebman, J. F.; Holmes, J. L.; Levin, R. D.; Mallard, W. G. J. Phys. Chem. Ref. Data 1977, 6, Suppl. 1.

25. Smith, D. L.; Wysocki, V. H. unpublished.

26. Žabka, J.; Fárník, M.; Dolejšek, Z.; Polách, J.; Herman, Z. Dynamics of the Hydride Ion Transfer Reaction between $\mathrm{CD}_{3}^{+}$ and $\mathrm{CH}_{4}$ : A Crossed Beam Scattering Study. J. Phys. Chem. 1995, 99, 15595-15601.

27. Meroueh, O.; Hase, W. L. Effect of Surface Stiffness on the Efficiency of Surface-Induced Dissociation. Phys. Chem. Chem. Phys. 2001, 3, 2306-2314.

28. Meroueh, O.; Hase, W. L. Dynamics of Energy Transfer in Peptide-Surface Collisions. J. Am. Chem. Soc. 2002, 124, 15241531. 